\title{
DETERMINAÇÃo DE PESTICIDAS NA ÁGUA E SEDIMENTO DO RIO PIQUIRI
}

\author{
Julio Cesar Rodrigues Azevedo" \\ Eliel R. Rolim de Moura** \\ Mauricius Marques dos Santos ${ }^{* * *}$
}

RESUMO: A qualidade da água e preservação dos ambientes aquáticos assumiu papel fundamental para a sustentabilidade, não só relacionado ao abastecimento, mas também à preservação destes ecossistemas. Os pesticidas fazem parte do grupo de poluentes que podem gerar impactos significativos nos ambientes em que são inseridos, impactos dos quais alguns ainda não são totalmente conhecidos. O objetivo deste estudo foi avaliar amostras de água e sedimento do Rio Piquiri, localizado em uma região de alta produção de trigo, soja e milho, no Estado do Paraná, Brasil. Este rio sofre influência direta da aplicação de pesticidas das lavouras da região. As amostras de água foram extraídas com uma mistura de diclorometano:hexano e as amostras de sedimento com uma mistura de acetona:hexano. Os extratos foram analisados em LC/MS/MS e confirmaram a presença dos herbicidas e fungicidas utilizados na região do estudo conforme dados oficiais de comercialização no período das coletas. Os resultados mais expressivos nas amostras de água foram do herbicida Atrazina $\left(0,030 \mu \mathrm{g} \mathrm{L}^{-1}\right)$ e do fungicida Carbendazim $\left(0,178 \mu \mathrm{g} \mathrm{L}^{-1}\right)$. No sedimento os maiores valores encontrados foram para os fungicidas Carbendazim $\left(26,8 \mu \mathrm{g} \mathrm{L}^{-1}\right)$ e Azoxistrobina $\left(0,712 \mu \mathrm{g} \mathrm{L}^{-1}\right)$, ambos na terceira coleta no ponto de coleta 3. Os resultados obtidos confirmaram a presença de resíduos de herbicidas e fungicidas na água e sedimento do Rio Piquiri, mas as concentrações obtidas não comprometem a potabilidade da água, devido aos valores estarem abaixo do Valor Máximo Permitido.

PALAVRAS-CHAVE: Atrazina; Carbendazim; Fungicidas; Herbicidas; LC/MS/MS.

\section{DETERMINATION OF PESTICIDES IN THE WATER AND SEDIMENT OF THE RIVER PIQUIRI}

\footnotetext{
Doutorado em Ecologia de Ambientes Aquáticos Continentais pela Universidade Estadual de Maringá, Pósdoutorado em Química Analítica na Universidade de Coimbra, Portugal; E-mail: jcrazevedo@hotmail.com

** Mestrando em Ciências e Tecnologia Ambiental pela Universidade Tecnológica Federal do Paraná (UTFPR), Brasil.

*** Discente de Doutorado em Engenharia Ambiental na University of Arizona, Arizona, Estados Unidos.
} 
ABSTRACT: The role of water quality and the preservation of aquatic environments are highly important for sustainability, with special reference to the ecosystems supply and preservation. Pesticides are pollutants that generate significant impacts on the environment, some of which are not totally known. Current research assesses water and sediment samples from the river Piquiri in a region featuring high production of wheat, soybean and corn in the state of Paraná, Brazil. In fact, the river Piquiri is directly affected by pesticides from the surrounding fields. Water samples were extracted with a mixture of hexane : dichloromethane and the sediment samples were extracted with a mixture of acetone : hexane. Extracts were analyzed in LC/MS/ MS and the presence of herbicides and fungicides used in the region under analysis was confirmed. Results of water samples revealed the herbicide atrazine $(0.030 \mu \mathrm{g}$ $\left.\mathrm{L}^{-1}\right)$ and the fungicide Carbendazim $\left(0,178 \mu \mathrm{g} \mathrm{L}^{-1}\right)$. The fungicides Carbendazim $(26.8$ $\left.\mu \mathrm{g} \mathrm{L}^{-1}\right)$ and Azoxistrobina $\left(0.712 \mu \mathrm{g} \mathrm{L}^{-1}\right)$ had the highest rates in the sediments in the third harvest at collection site 3 . Results confirm herbicide and fungicide residues in the water and sediment of the river Piquiri even though concentrations do not compromise water drinkability due to rates below the permitted maximum rate.

KEY WORDS: Atrazine; Carbendazim; Fungicides; Herbicides; LC/MS/MS.

\section{INTRODUÇÃO}

$\mathrm{Na}$ última década cerca de 11 milhões de substâncias químicas estavam registradas no CAS (Chemical Abstracts Service). Neste período, nos Estados Unidos e Japão, cerca de 100.000 compostos foram produzidos deliberadamente e utilizados para diversos fins. Destes, aproximadamente 3.000 compostos são produzidos em larga escala, com quantidades superiores a 500 toneladas por ano. Menos de $45 \%$ das novas substâncias foram submetidos a algum tipo de ensaio toxicológico básico e menos de $10 \%$ foram estudados quanto aos efeitos tóxicos sobre organismos em desenvolvimento (GHISELLI; JARDIM, 2007). Como exemplo podem ser citados os pesticidas, uma vez que muitas fórmulas destes compostos são manipuladas no Brasil e não existem estudos detalhados de muitos destes compostos.

$\mathrm{O}$ uso extensivo de pesticidas visando aumentar a produção agrícola e o intensivo desenvolvimento de novas moléculas aumentou significativamente a quantidade e variedade destes poluentes no ambiente (BAVCON; FRANCO; TREBSE, 
2007; RIBAS; MATSUMURA, 2009; HERNÁNDEZ-ACOSTA et al., 2013), muitas vezes provenientes do desconhecimento dos riscos dos produtos que utilizam e/ou da melhor técnica de sua aplicação.

A exposição ambiental das áreas próximas às lavouras, em função do uso de agroquímicos, depende das propriedades químicas do ingrediente ativo, dos agentes dispersantes da formulação, as doses e formas de aplicação e das características ambientais do local em que a aplicação ocorre (LEWIS et al., 1997; EL BAKOURI et al., 2009).

Os fatores que alteram a mobilidade e persistência dos agroquímicos estão relacionados ao regime de chuvas, intensidade do escoamento das águas superficiais, média do regime térmico, entre outros (NAVARRO et al., 2011). Por sua vez, a vulnerabilidade dos organismos não alvos depende da estrutura espacial e distribuição da biodiversidade da área (ARES, 2003).

A contaminação dos ambientes aquáticos por pesticidas se dá por aplicações intencionais, quando se quer combater uma praga na água como algas, moluscos, mosquitos. Ou por aplicações não intencionais, por diversos mecanismos como precipitação atmosférica, erosão do solo, efluentes industriais, esgoto sanitário, vazamentos durante o processamento, armazenamento e transporte, além das contaminações por pulverização e limpeza de equipamentos (SOLOMON et al., 2010). Independentemente da fonte de contaminação, estas substâncias apresentam efeitos indesejados nos ambientes aquáticos.

O destino dos pesticidas nos sistemas aquáticos é afetado pelas propriedades físicas e químicas da molécula, pela presença de outras substâncias na água, pH, temperatura e interação com o sedimento (SOLOMON et al., 2010).

Devido à sua habilidade de adsorver uma variedade de compostos orgânicos e inorgânicos, e seus subsequentes processos erosivos de entrada nos sistemas aquáticos, os sedimentos de muitos corpos aquáticos têm se tornado verdadeiras fontes de compostos químicos perigosos. Normalmente, estes compostos nocivos se acumulam no sedimento e seu processo de desorção e difusão em águas superficiais tem contribuído para a redução da qualidade da água e dos sedimentos destes ambientes (ZHOU et al., 2011).

Considerando esta realidade, provavelmente, o principal limitante para o desenvolvimento sustentável no início do presente século será a qualidade das águas. 
Primeiramente as águas superficiais e, em um segundo momento, as subterrâneas. Neste contexto, o monitoramento dos pesticidas, especialmente nos ambientes próximos à sua aplicação, constitui um importante indicador ambiental balizador de políticas públicas e ações de controle. Assim, este trabalho teve como objetivo determinar e quantificar a presença de pesticidas em amostras de água e sedimento do Rio Piquiri, Oeste do Estado do Paraná.

\section{MATERIAL E MÉTODOS}

\section{1 ÁREA DE ESTUDO}

A bacia hidrográfica do Rio Piquiri pertence à bacia hidrográfica do Paraná. A nascente do Rio Piquiri fica na Serra do São João, entre os municípios de Turvo e Guarapuava, com altitude inicial de 1.040 metros, chegando a 220 metros em sua foz, na margem do Rio Paraná, percorrendo $660 \mathrm{~km}$, apresentando área total de 24.721 $\mathrm{km}^{2}$ (SEMA, 2010). Os pontos amostrados apresentaram as seguintes coordenadas

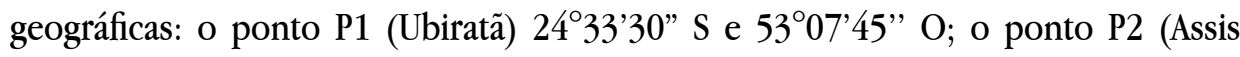

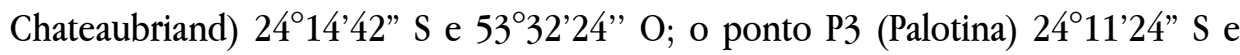

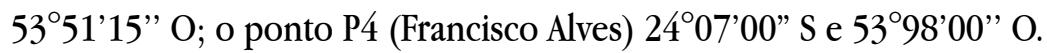

\subsection{ANÁLISE DE PESTICIDAS}

Foi realizada uma varredura qualitativamente de aproximadamente 80 pesticidas: abamectina, alacloro, aldicarbe, aldicarbesulfona, aletrina, ametrina, atrazina, azinfós etílico, azinfós metílico, azoxistrobina, bifentrina, carbofurano, carbosulfano, ciflutrina, cinoxamil, cipermetrinas, ciproconazol, ciprodinil, clofentezina, clomazona, clorfenvinfós, clorpirifós etílico, clorpirifós metílico, cresoxim metílico, carbaril, carbendazina deltametrina, diazinona, diclorvós, difenoconazol, dimetoato, disulfoton, diuron, epoxiconazol, etiona, fluazifop- $p$ butílico, fipronil, fentoato, flufenoxurom, fluometuron, flutriafol, forato, fosalona, fosfolan, fosmete, hexaconazol, hexazinona, hexitiazoxi, imazalil, imidacloprido, indoxacarbe, lambda-cialotrina, linuron, lufenuron, malationa, metalaxil metílico, 
metsulfurom metílico, metiocarbe, metolacloro, metidationa, mevinfós, oxamil, pirimicarbe, pirimifós etílico, profenofós, piriproxifem, procloraz, pirimifós metílico, promecarbe, prometrina, propanil, propargito, propiconazol, propoxur, simazina, tebuconazol, terbufós, tiabendazol, tiacloprido, tiofanato metílico, tiametoxan. Após a separação cromatográfica o analito foi para o espectrômetro de massas. Na câmara de ionização o analito foi transformado no íon principal ou íon precursor. Após a seleção do íon, este colidiu com o gás Hélio, gerando fragmentos iônicos (íons secundários). A varredura foi por monitoramento de múltiplas reações (Multiple Reaction Monitoring) - MRM - empregado para quantificar transição específica de um íon precursor para um íon secundário ( $\mathrm{m} / \mathrm{z}$ - precursor $\mathrm{m} / \mathrm{z}$ secundário).

As coletas de água e sedimento foram realizadas em setembro, outubro e dezembro de 2012 (C1 = set/12; C2 = out/12; e C3 = dez/12). O período das coletas esteve compreendido entre o preparo para o plantio da safra de verão de soja e milho e o fim da colheita do trigo na região.

Para a coleta das amostras de água foi utilizada garrafa de Van Dorn a 1,5 metros de profundidade em cinco subpontos equidistantes em aproximadamente 2 metros. Em cada subponto foi coletado 1 litro de água em garrafa de vidro âmbar, perfazendo um total de 5 litros que foram homogeneizados. Para a coleta das amostras de sedimento foi utilizada a draga de Petersen modificada. As coletas foram realizadas em três subpontos, sendo coletados aproximadamente 400 gramas de sedimento, perfazendo um total de 1,2 quilogramas, que foi homogeneizado (EMBRAPA, 2006).

As amostras de água e sedimento foram coletadas e preservadas a $4^{\circ} \mathrm{C}$ em caixas térmicas e, posteriormente, foram congeladas e armazenadas em freezer até o momento da extração. Ambas foram coletadas em pontos próximos à margem buscando evitar a ação da força hidráulica. O conceito de combinação de amostras simples e a limpeza dos frascos seguiram as recomendações da Embrapa (2006).

\subsection{EXTRAÇÃO E ANÁLISE CROMATOGRÁFICA}

Nas amostras de água, as análises de pesticidas foram realizadas em 1 litro de amostra de água filtrado em membrana de $13 \mathrm{~cm}$ de diâmetro e 0,22 $\mu \mathrm{m}$ de PVDF 
(fluoreto de polivinilideno) e posteriormente extraídas em funil de separação de 1 litro em três etapas: com uma solução de diclorometano:hexano 50:50 (duas vezes) e com diclorometano (uma vez). Os extratos foram concentrados à temperatura ambiente para $2 \mathrm{~mL}$, ressuspendidos em solução de metanol:água com $5 \mathrm{mmol}$ de acetato de amônio e transferidos para um vial de $2 \mathrm{~mL}$. O fator de concentração para as amostras de água foi de 500, o qual está de acordo com o método aplicado no Instituto de Tecnologia do Paraná - TECPAR (APHA, 2005).

Nas amostras de sedimento as análises de pesticidas foram realizadas em 10 gramas de sedimento seco em estufa a $40^{\circ} \mathrm{C}$. Estes sedimentos foram misturados com igual quantidade de sulfato de sódio anidro. A mistura foi macerada e eluída com $100 \mathrm{~mL}$ de solução acetona:hexano 50:50. Uma alíquota de $50 \mathrm{~mL}$ do extrato foi concentrada à temperatura ambiente para $2 \mathrm{~mL}$, ressuspendidos em solução de metanol:água com $5 \mathrm{mmol}$ de acetato de amônio e transferidos para um vial de 2 mL (ABNT, 1995).

Os extratos de sedimento e água foram analisados em um sistema de LC/MS/MS empregando cromatógrafo Agilent 1100 Series (Agilent Technologies, Waldbronn, AL), equipado com bomba quaternária e amostrador automático com capacidade para 100 frascos de injeção, acoplado a espectrômetro de massas triplo quadrupolo API 4000, Applied Biosystems/MDS Sciex (Sciex, Toronto, CA), com fonte de ionização Turbo VTM operado no modo de ionização TurboIonSpray® ("electrospray" - ESI).

A eluição cromatográfica foi realizada em coluna Eclipse XDB-C18, 5um, $150,0 \times 4,6 \mathrm{~mm}$, sob temperatura de $30^{\circ} \mathrm{C}$, fluxo de $0,5 \mathrm{~mL}$. O seguinte gradiente de eluição foi empregado: inicialmente eluição isocrática por 1,5 min com $70 \%$ (v/v) da fase A (solução 90/10 de água/metanol v/v contendo 5,0 mmol/L de acetato de amônio) e 30\% B (solução 95/5 de metanol/água v/v contendo 5,0 $\mathrm{mmol} \mathrm{L}^{-1}$ de acetato de amônio), rampa linear para $100 \%$ da fase B em 2 min e permanecendo nesta composição por mais $6 \mathrm{~min}$, depois retornando a condição inicial em 0,2 min e permanecendo nesta condição por mais 4 min, totalizando o tempo de análise de $12 \mathrm{~min}$, o volume de injeção foi de $40 \mathrm{uL}$. 


\section{RESULTADOS E DISCUSSÕES}

\subsection{AVALIAÇÃO DA CONTAMINAÇÃO, NAS AMOSTRAS DE ÁGUA E SEDIMENTO, POR PESTICIDAS}

Com base nos dados de comercialização de pesticidas no período de 01 de março de 2012 a 01 de janeiro de 2013, fornecidos pela Agência de Defesa Agropecuária do Paraná (ADAPAR), foi possível levantar a quantidade disponível de cada Ingrediente Ativo (IA) na região do estudo. A partir dos volumes comercializados, foi usada a concentração nominal de cada marca comercial por ingrediente ativo específico. Desta forma, foi possível obter a quantidade em massa dos ingredientes ativos (IA) empregados na região do estudo. Como exemplo se pode citar massa do IA da clomazona, utilizado próximo ao Rio Piquiri (Tabela 1), na cultura de fumo, mandioca e soja e verificar sua possível presença nos resultados positivos obtidos na água e sedimento.

O mesmo levantamento foi realizado para todos os pesticidas com resultados positivos utilizando os dados do volume comercializado fornecidos pela ADAPAR. A Tabela 1 indica a quantidade disponível de cada IA dos pesticidas com resultados positivos para a região coberta por todos os pontos de coleta.

Tabela 1. Quantidade de Ingrediente Ativo comercializada no período da coleta

\begin{tabular}{lc}
\hline \multicolumn{1}{c}{ INGREDIENTE ATIVO } & QUANTIDADE $(\mathrm{kg})$ \\
\hline Ametrina & 20,90 \\
Atrazina & 4048 \\
Azoxistrobina & 1053 \\
Carbendazim & 903 \\
Clomazona & 173 \\
Metolacloro & 24 \\
Simazina & 13 \\
\hline
\end{tabular}

Fonte: Dados da pesquisa 
Há pelo menos 18 anos, tem-se conhecimento que o agricultor brasileiro não tem a prática consolidada de estocar quantidades significativas de pesticidas por longos períodos, principalmente por questões relacionadas ao custo de produção e ao baixo nível da inflação nos últimos anos. Baseado nesta cultura de produção agrícola e nos volumes comercializados no período, provavelmente, a maior parte dos produtos adquiridos foi utilizada no fim das safras de inverno (fungicidas, principalmente para o trigo) e no início das safras de verão (herbicidas, principalmente para soja e milho), nos períodos das coletas realizadas. Dos pesticidas avaliados, foram encontrados resultados positivos para sete deles nas amostras de água (Tabela 2) e cinco nas amostras de sedimento (Tabela 3).

No sedimento foram obtidos valores maiores que os das amostras de água sendo os resultados mais expressivos também para atrazina e carbendazim.

O carbendazim, em função de seu caráter mais lipofílico, tem mais afinidade com a matéria orgânica presente no sedimento, proveniente da sua baixa solubilidade. Já a atrazina, que possui caráter mais hidrofílico, apresenta maior mobilidade na água (IPCS, 2015). A presença de ambos em maiores quantidades no sedimento que a concentração obtida na água reforça o aspecto do acúmulo de poluição dos sedimentos devido à interação com o material particulado.

Tabela 2. Resultados encontrados nas amostras de água $\left(\mu \mathrm{g} \mathrm{L}^{-1}\right)$ dos quatro pontos amostrados no Rio Piquiri nas coletas de set/12 (C1), out/12 (C2) e dez/12 (C3)

(Continua)

\begin{tabular}{ccccccccc}
\hline COLETA & & Amet $^{\mathrm{a}}$ & Atra $^{\mathrm{b}}$ & Azox $^{\mathrm{c}}$ & Carb $^{\mathrm{d}}$ & Clom $^{\mathrm{e}}$ & Metol $^{\mathrm{f}}$ & Sima $^{\mathrm{g}}$ \\
\hline \multirow{6}{*}{ C1 } & P1 & $1,6.10^{-4}$ & $3,7.10^{-3}$ & $5,7.10^{-5}$ & $1,8.10^{-1}$ & $3,1.10^{-4}$ & $6,6.10^{-4}$ & ND \\
& P2 & $3,8.10^{-4}$ & $2,4.10^{-3}$ & $5,4.10^{-4}$ & $9,0.10^{-3}$ & $2,5.10^{-4}$ & $7,8.10^{-4}$ & ND \\
& P3 & $2,0.10^{-4}$ & $1,8.10^{-3}$ & $3,7.10^{-4}$ & $2,6.10^{-2}$ & $5,8.10^{-4}$ & $6,6.10^{-4}$ & ND \\
& P4 & $2,8.10^{-4}$ & $2,3.10^{-3}$ & $5,0.10^{-4}$ & $6,0.10^{-3}$ & $2,4.10^{-4}$ & $8,6.10^{-4}$ & ND \\
\hline \multirow{4}{*}{ C2 } & P1 & ND & $2,3.10^{-2}$ & $1,5.10^{-3}$ & $1,2.10^{-4}$ & $1,6.10^{-4}$ & ND & $1,9.10^{-3}$ \\
& P2 & $4,7.10^{-4}$ & $30.10^{-2}$ & $2,2.10^{-4}$ & $3,4.10^{-4}$ & $2,1.10^{-3}$ & $5,9.10^{-4}$ & $2,0.10^{-3}$ \\
& P3 & $1,3.10^{-3}$ & $1,2.10^{-2}$ & ND & $4,7.10^{-4}$ & $1,2.10^{-3}$ & $1,3.10^{-4}$ & $3,3.10^{-4}$ \\
& P4 & $1,9.10^{-4}$ & $7,5.10^{-3}$ & ND & $2,9.10^{-4}$ & $6,5.10^{-4}$ & ND & $1,2.10^{-3}$ \\
\hline
\end{tabular}


(Conclusão)

\begin{tabular}{ccccccccc}
\hline COLETA & & Amet $^{\mathrm{a}}$ & Atra $^{\mathrm{b}}$ & Azox $^{\mathrm{c}}$ & Carb $^{\mathrm{d}}$ & Clom $^{\mathrm{e}}$ & Metol $^{\mathrm{f}}$ & Sima $^{\mathrm{g}}$ \\
\hline \multirow{6}{*}{ C3 } & P1 & $1,3.10^{-4}$ & $1,2.10^{-2}$ & $6,2.10^{-4}$ & $7,9.10^{-4}$ & ND $^{*}$ & $1,7.10^{-4}$ & $1,1.10^{-3}$ \\
& P2 & $4,3.10^{-4}$ & $8,4.10^{-3}$ & $3,7.10^{-4}$ & $1,5.10^{-3}$ & $1,9.10^{-4}$ & $2,8.10^{-4}$ & ND \\
& P3 & $1,6.10^{-4}$ & $3,4.10^{-3}$ & $1,6.10^{-4}$ & $2,0.10^{-4}$ & $2,2.10^{-4}$ & $3,5.10^{-4}$ & ND \\
& P4 & $2,1.10^{-4}$ & $7,2.10^{-3}$ & $2,1.10^{-4}$ & $1,0.10^{-3}$ & $2,5.10^{-4}$ & $1,7.10^{-4}$ & ND \\
\hline
\end{tabular}

a ametrina; ${ }^{b}$ atrazina; ${ }^{\mathrm{C}}$ azoxistrobina; ${ }^{\mathrm{d}}$ carbendazim; ${ }^{\mathrm{e}}$ clomazona; ${ }^{\mathrm{f}}$ metolacloro; simazina ${ }^{\mathrm{g}}$; ND - Não Detectado.

Fonte: Dados da pesquisa

Tabela 3. Resultados obtidos nas amostras de sedimento $\left(\mu \mathrm{g} \mathrm{Kg}^{-1}\right)$ dos quatros pontos amostrados no Rio Piquiri nas coletas de set/12 (C1), out/12 (C2) e dez/12 (C3)

\begin{tabular}{|c|c|c|c|c|c|c|}
\hline \multicolumn{2}{|c|}{ COLETA } & Amet $^{\mathrm{a}}$ & $\operatorname{Atra}^{\mathrm{b}}$ & $\mathrm{Azox}^{\mathrm{C}}$ & Carb $^{\mathrm{d}}$ & Metol $^{\mathrm{e}}$ \\
\hline \multirow{4}{*}{$\mathrm{C} 1$} & P1 & ND & $5,1 \cdot 10^{-2}$ & ND* & $9,4.10^{-2}$ & $\mathrm{ND}^{*}$ \\
\hline & P2 & ND & $3,5.10^{-2}$ & $2,2.10^{-2}$ & $2,3.10^{-1}$ & ND \\
\hline & P3 & ND & $4,0.10^{-2}$ & $6,5 \cdot 10^{-2}$ & $1,0.10^{-1}$ & $\mathrm{ND}^{*}$ \\
\hline & $\mathrm{P} 4$ & ND & ND & $4,1.10^{-2}$ & $4,5.10^{-2}$ & ND \\
\hline \multirow{4}{*}{$\mathrm{C} 2$} & P1 & ND & $4,9.10^{-2}$ & ND* & $4,7.10^{-2}$ & $\mathrm{ND}^{*}$ \\
\hline & $\mathrm{P} 2$ & $2,2.10^{-2}$ & $1,1.10^{-1}$ & $5,1.10^{-2}$ & $7,5 \cdot 10^{-2}$ & $2,0.10^{-2}$ \\
\hline & $\mathrm{P} 3$ & $1,4.10^{-1}$ & $6,6.10^{-2}$ & $2,2.10^{-2}$ & $5,6.10^{-2}$ & $2,0.10^{-2}$ \\
\hline & P4 & $6,3 \cdot 10^{-2}$ & $4,0.10^{-2}$ & ND* & $7,3 \cdot 10^{-2}$ & ND* \\
\hline \multirow{4}{*}{$\mathrm{C} 3$} & P1 & ND & ND & ND* & $2,3.10^{-1}$ & $\mathrm{ND}^{*}$ \\
\hline & P2 & ND & ND & ND & ND & ND \\
\hline & P3 & ND & $2,1.10^{-1}$ & $7,1 \cdot 10^{-1}$ & 26,8 & $2,4.10^{-2}$ \\
\hline & $\mathrm{P} 4$ & ND & ND & ND* & $9,3 \cdot 10^{-2}$ & ND* \\
\hline
\end{tabular}

ND - Não Detectado; ND* - Traço abaixo do menor ponto da curva de calibração.

Fonte: Dados da pesquisa

A mobilidade na água para a atrazina é considerada alta conforme o critério de Goss (BRITO et al., 2001). Porém, a incidência de chuvas na região no período das coletas foi relativamente baixa, conforme dados do Instituto Meteorológico SIMEPAR, com precipitações médias de $0,03 \mathrm{~mm}, 1,54 \mathrm{~mm}$ e 1,85 mm nas coletas $\mathrm{C} 1$, 
C2 e C3, respectivamente. Provavelmente, este período de chuvas baixas favoreceu pouco o transporte da atrazina, aplicada nas plantações, para o Rio Piquiri. Segundo Mudhoo e Garg (2011), apenas de 0,1 a 3,0\% da carga de atrazina aplicada têm arraste para águas superficiais próximas às lavouras como destino. Já o carbendazim apresenta baixa mobilidade na água, conforme o critério de Goss, sendo menos afetado pelos aspectos de precipitação.

A degradação da atrazina no solo se dá por uma grande variedade de microorganismos, mais especificamente cepas bacterianas como as Pseudomonas, Agrobacterium radiobacter 144 e Nocardioides $s p$, capazes de mineralizar este pesticida a dióxido de carbono (MUDHOO; GARG, 2011). Este processo consome a maior parte da atrazina residual, após a aplicação em campo. Alguns autores demonstram o significativo crescimento destes microorganismos em função da oferta de atrazina em amostras de solo (CHEYNS et al., 2010; CHEYNS et al., 2012). Esta degradação também pode estar relacionada à baixa concentração de atrazina obtida nas amostras de água.

De maneira geral, as cepas e comunidades microbianas no solo apresentam maior atividade de degradação para os pesticidas quando da aplicação contínua, que é uma prática recorrente nas monoculturas agrícolas (YU et al., 2010). Testes realizados por Yu et al. (2010) indicam uma redução aproximada de dez vezes na meia-vida do carbendazim entre a primeira e a quarta aplicação no solo.

Cepas e comunidades microbianas que consomem os poluentes são selecionadas com o tempo em função da aplicação frequente dos mesmos pesticidas aumentando significativamente a capacidade de degradação. Além da degradação, a entrada de carbendazim no solo implica na disponibilidade de nutrientes no ambiente, considerando que esta molécula tem 23\% de N e 56\% de C (WANG et al., 2009; YU et al., 2010).

\subsection{POTENCIAL DE CONTAMINAÇÃO DE ÁGUAS SUBTERRÂNEAS E SUPERFICIAIS}

Conforme o método screening da Agência de Proteção Ambiental dos Estados Unidos (EPA), método de Goss e Groundwater Ubiquity Score/GUS (BRITO et al., 
2001) que consideram as propriedades físicas e químicas dos poluentes (Tabela 4). De acordo com o método de GUS, os resultados positivos dos poluentes avaliados na região do estudo, todos são considerados de alto potencial contaminante (PRIMEL et al., 2005; MILHOME et al., 2009).

Já na avaliação pelo método Goss, índice para águas superficiais, foram classificadas como Baixo Potencial de Transporte Associado ao Sedimento (BPTAS) a ametrina, atrazina, carbendazim e metolacloro. Como Alto Potencial de Transporte Dissolvido em Água (APTDA) foram classificadas a ametrina, atrazina, azoxistrobina, clomazona e simazina.

Tabela 4. Propriedades Físicas e Químicas para os pesticidas encontrados na região do estudo

\begin{tabular}{lcccccccc}
\hline \multicolumn{1}{c}{ Pesticidas } & $\begin{array}{c}\mathrm{S} \\
\left(\mathrm{mg} \mathrm{L}^{-1}\right)\end{array}$ & $\begin{array}{c}\mathrm{K}_{\mathrm{oc}} \\
\left(\mathrm{m} \mathrm{L} \mathrm{L}^{-1}\right)\end{array}$ & $\begin{array}{c}\mathrm{K}_{\mathrm{H}} \\
\left(\mathrm{mg} \mathrm{L}^{-2}\right)\end{array}$ & $\mathrm{pK}_{\mathrm{a}}$ & $\begin{array}{c}\log \\
\mathrm{K}_{\mathrm{ow}}\end{array}$ & $\begin{array}{c}\text { DT50 } \\
(\text { dias })\end{array}$ & $\begin{array}{c}\text { DT50 agua } \\
(\text { dias })\end{array}$ & GUS \\
\hline Ametrina & 200 & 316 & $4,1.10^{-4}$ & 10,07 & 2,63 & 37 & $\mathrm{MP}$ & 0,46 \\
Atrazina & 35 & 100 & $1,5.10^{-4}$ & 1,70 & 2,7 & 29 & 2,6 & 3,3 \\
Azoxistrobina & 6,7 & 589 & $7,4.10^{-9}$ & $\mathrm{NA}$ & 2,5 & 180,7 & 6,1 & 2,6 \\
Carbendazim & 8,0 & 234 & $3,6.10^{-3}$ & 4,2 & 1,48 & 22 & 7,9 & 2,64 \\
Clomazona & 1102 & 300 & $4,2.10^{-3}$ & $\mathrm{NA}$ & 2,54 & 42,5 & $\mathrm{MP}$ & 2,96 \\
Metolacloro & 530 & 120 & $2,4.10^{-3}$ & $\mathrm{NA}$ & 3,4 & 21 & 88 & 3,49 \\
Simazina & 5 & 130 & $5,6.10^{-5}$ & 1,62 & 2,3 & 90 & 96 & 2,0 \\
\hline
\end{tabular}

NA - Não Aplicável; MP - Muito Persistente; S: solubilidade em água; $K_{o c}$ : coeficiente de adsorção à matéria orgânica do solo; $\mathrm{K}_{\mathrm{H}}$ : constante da lei de Henry; pKa a constante de dissociação; $\mathrm{K}_{\mathrm{ow}}$ : coeficiente de partição octanol-água; DT50 ${ }_{\text {solo }}$ : meia-vida do composto no solo; DT50 agua : meia-vida do composto na água.

\subsection{VARIAÇÃO DA CONCENTRAÇÃO DE ALGUNS HERBICIDAS}

Dos principais cultivos da região, o milho e a soja ocuparam a maior área das plantações, seguidos pelo trigo que na época da primeira coleta estava no período de fim da safra e colheita. Nesta época ocorreu a aplicação de fungicidas e alguns inseticidas para o preparo da primeira fase das safras de verão de milho e soja.

A variação da concentração de atrazina nas amostras de água ao longo das coletas consta na Figura 1A. 

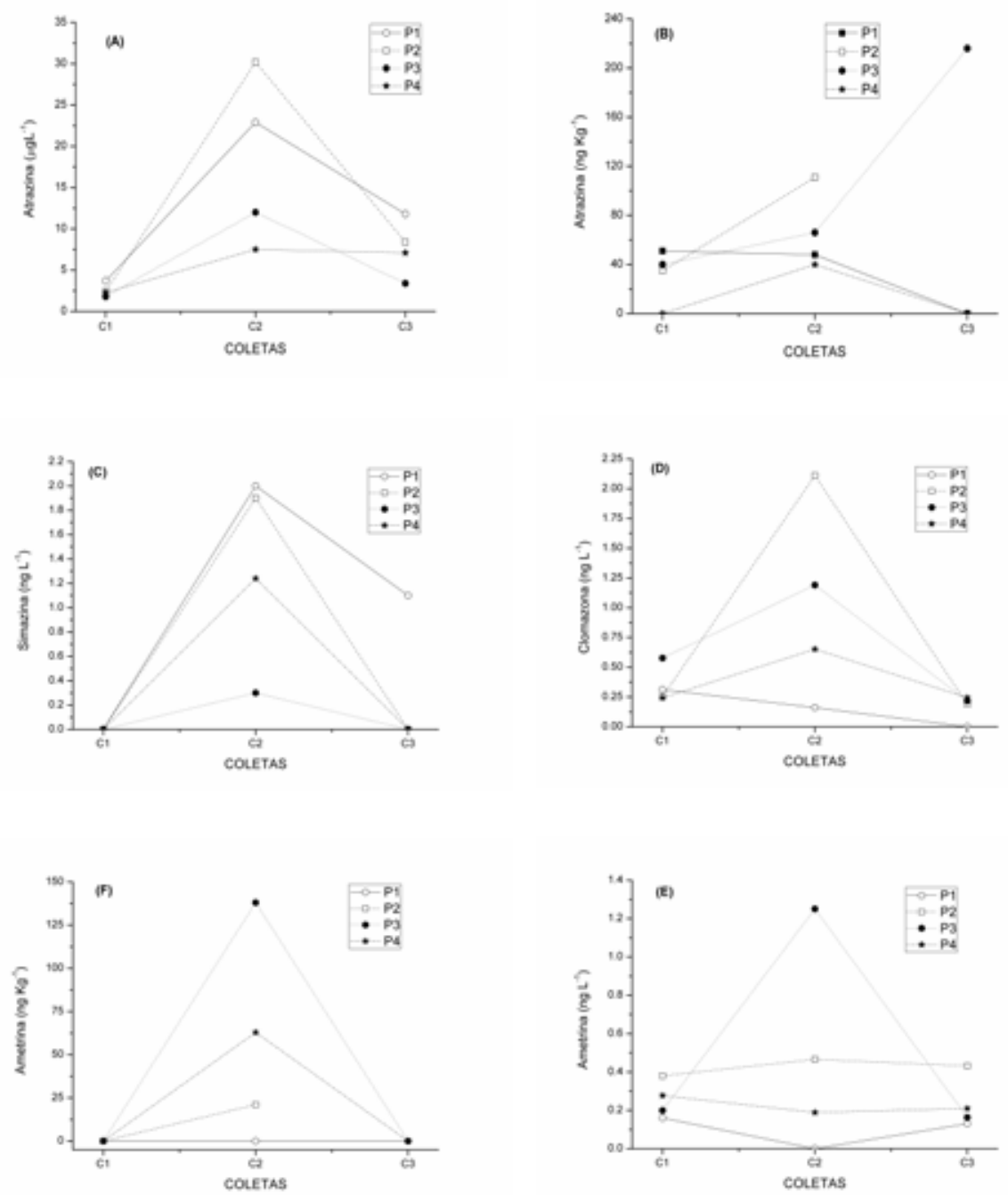

Figura 1. Variação da concentração de atrazina na água (A) e no sedimento (B), simazina na água (C), clomazona na água (D), ametrina na água (E) e no sedimento (F) nas amostras do Rio Piquiri, nas coletas de set/12 (C1), out/12 (C2) e dez/12 (C3).

O comportamento da atrazina no sedimento apresentou perfil similar ao apresentado na água. Este aspecto é reforçado pelos valores de $\mathrm{K}_{\mathrm{ow}}$ para as triazinas, demonstrando sua maior afinidade com as frações polares dos compartimentos ambientais (Figura 1B). A exceção ficou por conta do ponto 3 na coleta 3 que 
apresentou aumento da presença do herbicida, provavelmente pela afinidade deste herbicida com alguma fração do sedimento neste ponto de coleta.

Os mesmos padrões descritos para a Atrazina nas amostras de água são verificados para outro herbicida do grupo das triazinas e a simazina (Figura 1C).

Para a clomazona, herbicida utilizado principalmente para a cultura de soja, foi observado um padrão similar aos herbicidas utilizados na dessecação, à exceção do ponto 1, região com maior densidade de plantio de trigo e outras culturas (Figura 1D). O padrão similar de decaimento pode ter sido favorecido pela alta solubilidade em água quando comparado a outros herbicidas como as triazinas e o metolacloro (Tabela 4).

A ametrina compõe o grupo das triazinas detectadas. Este composto também apresenta valores $\mathrm{K}_{\mathrm{ow}}$ similares, porém, sua maior resistência à fotodegradação e boa estabilidade em águas de $\mathrm{pH}$ neutro resultaram em um perfil diferente das demais triazinas (Figura 1E). Para esta triazina específica (ametrina), foram observadas maiores concentrações, no sedimento, na coleta 2 (Figura 1F). As concentrações de ametrina na amostra de água e sedimento no ponto 3 foram maiores, provavelmente, em função da maior densidade do cultivo de mandioca nesta região.

Já o metolacloro apresenta um padrão inverso aos demais herbicidas citados (Figura 2). Provavelmente, duas aplicações distintas deste produto ocorreram no período das coletas na região, próximo das coletas 1 e 3, sendo a aplicação no período próximo a coleta 1 mais significativa. A sua solubilidade em água é maior que a das triazinas (Tabela 4).

Apesar de o metolacloro ter maior valor de $\mathrm{K}_{\mathrm{ow}}$, relativamente aos herbicidas presentes nas amostras, sua meia-vida é significativamente menor. Este aspecto, provavelmente, explica a ausência deste poluente no sedimento em quantidades detectáveis por este processo. 


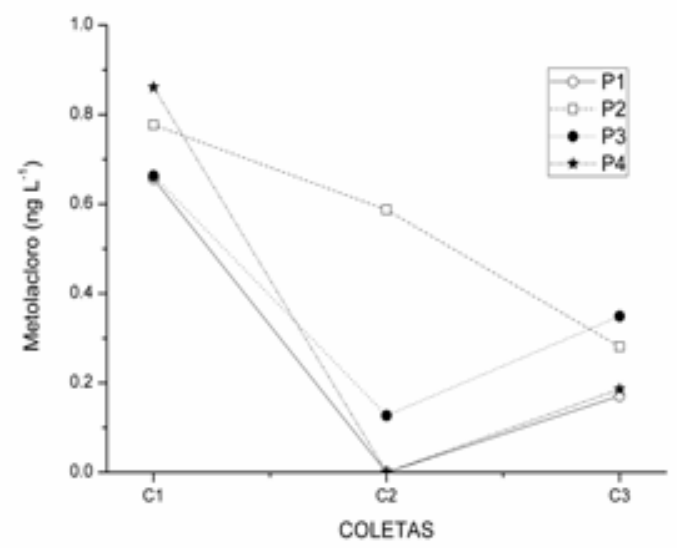

Figura 2. Variação da concentração de metolacloro nas amostras de água do Rio Piquiri, nas coletas de set/12 (C1), out/12 (C2) e dez/12 (C3).

\subsection{VARIAÇÃO DA CONCENTRAÇÃO DE ALGUNS FUNGICIDAS}

Os resultados encontrados na água para a azoxistrobina indicam duas prováveis aplicações (Figura 3A). A primeira foi no fim do cultivo de trigo e a segunda no final de ciclo da cultura de soja. Considerando que o final de ciclo do milho precoce não foi contemplado durante o período de coletas, provavelmente, as aplicações detectadas na coleta 3 foram provenientes das aplicações na soja.

Os fungicidas do grupo das estrobilurinas, do qual a azoxistrobina faz parte, têm sido amplamente utilizados na região do estudo no combate à ferrugem da soja, combinadas aos fungicidas de outros grupos como os triazóis. Seu decaimento evidenciado na coleta 2, após aplicação no trigo, provavelmente, seja em função de sua alta fotólise em valores de $\mathrm{pH}$ encontrados neste ambiente aquático (próximos de sete). A variação da concentração da azoxistrobina no sedimento (Figura 3B), provavelmente, devido a seu $\mathrm{K}_{\mathrm{ow}}$ ser relativamente baixo foi diferente ao observado dissolvido na água, mas com concentrações mais elevadas, indicando um possível acúmulo no sedimento.

O carbendazim foi utilizado para os três cultivos principais da região, porém, em períodos diferentes. Para o trigo, o final do ciclo foi a época de aplicação, 
imediatamente anterior à coleta 1. Provavelmente, os altos valores encontrados na água (Figura 3C) sejam em função desta aplicação. Na coleta 2, o significativo decaimento deste poluente pode ser atribuído primeiramente ao baixo $\mathrm{K}_{\text {ow }} \mathrm{e}$ em segundo lugar à sua curta meia-vida na fase aquosa. Em contraponto a estas características, o carbendazim é considerado estável em relação à suas fotólise e hidrólise aquosas, sendo resistente à degradação em ambientes com pH entre 5 e 7 (PPDB, 2013).
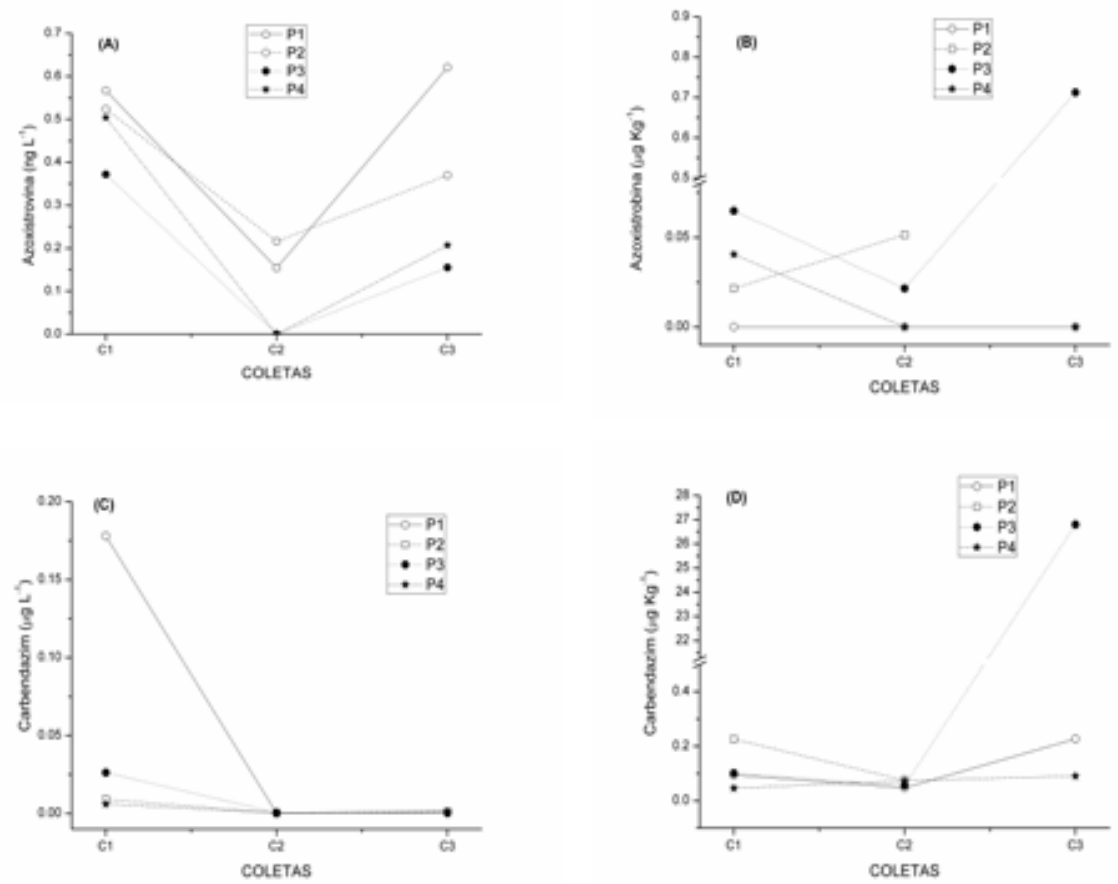

Figura 3. Variação da concentração de azoxistrobina na água (A) e no sedimento (B) e do carbendazim na água (C) e no sedimento (D) nas amostras do Rio Piquiri, nas coletas de set/12 (C1), out/12 (C2) e dez/12 (C3).

O aumento deste poluente no sedimento na coleta 3 (Figura 3D), provavelmente, seja em função da acumulação das aplicações do carbendazim em lavouras precoces, uma vez que a aplicação na soja se dá do meio para o final do ciclo. A ligação do carbendazim ao sedimento talvez possa ser atribuída ao efeito 
sinergético relacionado a outros agroquímicos presentes neste ambiente como os fertilizantes ou a metais presentes no solo como demonstrado por Li et al. (2011).

A diferença entre as quantidades de ingredientes ativos (IA) aplicadas na região e as encontradas nas amostras de água e sedimento podem ser justificadas principalmente pela diluição dos produtos formulados, mobilidade e degradação do IA na água, mobilidade no solo (Tabela 4) e degradação do IA por microorganismos presentes no solo (SOLOMON et al., 2010; MUDHOO; GARG, 2011; ZHOU et al., 2011).

A diluição dos produtos formulados tem influência direta na degradação dos ingredientes ativos principalmente em função da fotólise e hidrólise dos pesticidas em meio aquoso. Esta diluição é orientada pelo fabricante do pesticida para a preparação da calda de aplicação. Segundo Cheyns et al. (2010), as caldas têm concentração em torno de $0,5 \mathrm{~g} \mathrm{~L}^{-1}$ de pesticidas. Em média, quantidades de 1 a 4 litros ou quilogramas do produto podem ser diluídas em caldas de 200 a 400 litros de água, para a maioria dos produtos comercializados no país (ANDREI, 2009).

As doses de produto formulado são definidas quando da aprovação do registro do pesticida pelos ministérios competentes e compõem a bula que acompanha o produto. Por exemplo, um dos fabricantes da atrazina indica a aplicação máxima de $3,25 \mathrm{~kg} /$ ha de IA. Portanto, esta aplicação resultará em uma carga de $0,5 \mathrm{~g} / \mathrm{m}^{2}$ de IA (ANDREI, 2009).

Conforme comentado anteriormente, alguns autores indicam que a aplicação sucessiva de pesticidas no solo seleciona microorganismos aptos a degradar quantidades significativas destes poluentes (YU et al., 2010; CHEYNS et al., 2012). Esta condição aliada às diluições empregadas em campo justificam as baixas concentrações encontradas na água e no sedimento do Rio Piquiri.

De acordo com a Portaria $\mathrm{n}^{\circ}$ 2.914, de 12 de dezembro de 2011, do Ministério da Saúde, os limites de potabilidade para a Atrazina, Carbendazim, Metolacloro e Simazina são comparados às concentrações obtidas (Tabela 5). Os demais poluentes detectados não apresentam Valor Máximo Permitido (VMP) na Portaria no 2.914. 
Tabela 5. Resultados da concentração dos principais pesticidas encontrados na água com o Valor Máximo Permitido (VMP) pela Portaria no 2.914, de 2011

\begin{tabular}{lccc}
\hline \multicolumn{1}{c}{ PESTICIDA } & $\begin{array}{c}\text { VMP } \\
\left(\mu \mathrm{L}^{-1}\right)\end{array}$ & $\begin{array}{c}\text { Maior Concentração } \\
\left(\mu \mathrm{L}^{-1}\right)\end{array}$ & $\begin{array}{c}\text { Razão } \\
(\text { VMP/conc.) }\end{array}$ \\
\hline Atrazina & 2,0 & $30,2.10^{-2}$ & 70 \\
Carbendazim & 120 & $2,62.10^{-2}$ & 4500 \\
Metolacloro & 10 & $8,61.10^{-4}$ & 11000 \\
Simazina & 2,0 & $1,96.10^{-3}$ & 1000 \\
\hline
\end{tabular}

Fonte: Dados da pesquisa

De acordo com estes resultados obtidos nos pontos de coleta, a presença de pesticidas não foi suficiente para comprometer a potabilidade da água conforme portaria referente. Os valores máximos de atrazina foram 70 vezes abaixo do Valor Máximo Permitido (VMP) pela Portaria ${ }^{\circ} 2.914$, de 2011; para o carbendazim foram de 4500 vezes; para o metolacloro de 11000 ; e para a simazina de 1000 vezes abaixo do VMP.

\section{CONCLUSÕES}

Os resultados obtidos confirmaram a presença de resíduos das aplicações de herbicidas e fungicidas na água e sedimento do Rio Piquiri, sendo que os mesmos estão mais relacionados à aplicação dos produtos em campo (com as safras realizadas).

De acordo com estes resultados obtidos nos pontos de coleta, a presença de pesticidas não foi suficiente para comprometer a potabilidade da água conforme os valores máximos de pesticidas determinados e o VMP, pois estiveram sempre muito abaixo destes valores.

Porém, apesar dos valores serem considerados relativamente baixos, a toxicidade para os demais constituintes desse ecossistema deve ser considerada e avaliada como, por exemplo, a comunidade bentônica. 


\section{AGRADECIMENTOS}

Ao CNPq pelo financiamento (Processo 474900/2011-8); à Fundação Araucária (Bolsa PQ); à CAPES pelo apoio através de bolsa de estudos, à UTFPR, ao CT-Infra 2010 e 2011/FINEP pelos Recursos FNDCT, subprojeto NIPTA - Núcleo Interdisciplinar de Pesquisa em Tecnologias Ambientais.

\section{REFERÊNCIAS}

ANDREI, E. Compêndio de defensivos agrícolas. 8. ed. São Paulo: Andrei, 2009.

APHA. Standards Methods for the Examination of water and wastewater, 6630B: Liquid-Liquid Extraction Gas Chromatographic Method. 21. ed. 2005.

ARES, J. Time and space issues in ecotoxicology: populations models, landscape pattern analysis and long range environmental chemistry. Environmental Toxicology and Chemistry, v. 22, p. 945-957, 2003.

ASSOCIAÇÃO BRASILEIRA DE NORMAS TÉCNICAS - ABNT. NBR 13408: Sedimento - Determinação de resíduos de pesticidas organoclorados por cromatografia gasosa - Método de ensaio. Rio de Janeiro: ABNT, 1995.

SEMA. Bacias Hidrográficas do Paraná: série histórica. In: BARBOSA, M. C.; SCROCCARO, P. J. L. (Org.). Governo do Estado do Paraná. Secretaria de Estado do Meio Ambiente e Recursos Hídricos - SEMA. 2010. p. 1-60.

BAVCON, K. M.; FRANCO, M.; TREBSE, P. Photodegradation of organophosphorus insecticides: investigations of products and their toxicity using gas chromatographymass spectrometry and AChE-thermal lens spectrometric bioassay. Chemosphere, v. 67, p. 99-107, 2007.

BRITO, N. M.; AMARANTE, P. Jr.; ABAKERLI, R.; SANTOS, T. C. R.; RIBEIRO, M. L. Risco de contaminação de águas por pesticidas aplicados em plantações de eucaliptos e coqueiros: análise preliminar. Pesticidas: Revista de Ecotoxicologia e Meio Ambiente, v. 11, p. 93-104, 2001. 
CHEYNS, K.; MERTENS, J.; DIELS, J.; SMOLDERS, E.; SPRINGAEL, D. Monod kinetics rather than a first-order degradation model explains atrazine fate in soil minicolumns: Implications for pesticide fate modelling. Environmental Pollution, v. 158, p. 1405-1411, 2010.

CHEYNS, K.; MARTIN-LAURENT, F.; BRU, D.; AAMAND, J.; VANHAECKE, L.; DIELS, J.; MERCK, R.; SMOLDERS, E.; SPRINGAEL, D. Long-term dynamics of atrazine mineralization potential in surface and subsurface soil in an agricultural fiel as a response to atrazine aplications. Chemosphere, v. 86, p. 1028-1034, 2012.

EL BAKOURI, H.; MORILLO, J.; USERO, J.; OUASSINI, A. Natural attenuation of pesticide water contamination by using ecological adsorbents: Application for chlorinated pesticides included in European Water Framework Directive. Journal of Hydrology, v. 364, p. 175-181, 2009.

EMPRESA BRASILEIRA DE PESQUISA AGROPECUÁRIA - EMBRAPA. Manual de procedimentos de coleta de amostras emáreas agrícolas para análise da qualidade ambiental. Jaguariúna: Embrapa Meio Ambiente, 2006.

GHISELLI, G.; JARDIM, W. F. Interferentes endócrinos no ambiente. Química Nova, v. 30, p. 695-706, 2007.

HERNÁNDEZ-ACOSTA, L.; QUÉ-RAMOS, F. J.; PIÑA-GUZMÁN, A. B.; CANEPA, J. R. L. Uso de plaguicidas en Zonas Cañeras del Municipio de Cárdenas Tabasco, México: posible impacto ambiental y a la salud. Revista AIDIS de Ingenieria y Ciencias Ambientales: Investigación, desarrollo y practica, v. 6, n. 2, p. 1-11, 2013.

INTERNATIONAL PROGRAMME ON CHEMICAL SAFETY - IPCS. Carbendazim. Disponível em: < http://www.inchem.org/documents/ehc/ehc/ehc149.htm > Acesso em: 12 ago. 2015.

LEWIS, K. A.; NEWBOLD, M. J.; HALL, A. M.; BROOM, C. E. Eco-rating system for optimizing pesticide use at farm level. Part 2: Evaluation, Examples and Piloting. Journal of Agricultural Engineering Research, v. 68, p. 281-289, 1997. 
LI, X.; ZHOU, Q.; WEI, S.; REN, W. Adsorption and desorption of carbendazim and cadmium in typical soils in northeastern China as affected by temperature. Geoderma, n. 160, p. 347-354, 2011.

MILHOME, M. A. L.; SOUSA, D. O. B.; LIMA, F. A. F.; NASCIMENTO, R. F. Avaliação do potencial de contaminação de águas superficiais e subterrâneas por pesticidas aplicados na agricultura do Baixo Jaguaribe, CE. Engenharia Sanitária Ambiental, v. 14, n. 3, p. 363-372, 2009.

MUDHOO, A.; GARG, V. K. Sorption Transport and transformation of atrazine in soils, minerals and composts: a review. Pedosphere, v. 21, n. 1, p 11-25, 2011.

NAVARRO, S.; FENOLL, J.; VELA, N.; RUIZ, E.; NAVARRO, G. Removal of ten pesticides from leaching water at pilot plant scale by photo-Fenton treatment. Chemical Engineering Journal, n. 167, p. 42-49, 2011.

PRIMEL, E. G.; ZANELLA, R.; KURZ, M. H. S.; GONCALVES, F. F.; MACHADO, S. O.; MARCHEZAN, E. Poluição das águas por herbicidas utilizados no cultivo do arroz irrigado na região central do estado do Rio Grande do Sul, Brasil. Química Nova, v. 28, p. 605-609, 2005.

PESTICIDE PROPERTIES DATABASE - PPDB. Disponível em: < http://sitem.herts. ac.uk/aeru/footprint/index2.htm > . Acesso em: 15 abr. 2013.

RIBAS, P. P.; MATSUMURA, A. T. S. A química dos agrotóxicos: impacto sobre a saúde e meio ambiente. Revista Liberato, v. 10, n. 14, p. 149-158, 2009.

SOLOMON, K. R.; STEPHENSON, G. R.; CORRÊA, L.; ZAMBRONE, F. A. D. Praguicidas e o Meio Ambiente. São Paulo: ILSI - International Life Sciences Institute, 2010.

WANG, X.; SONG, M.; GAO, C.; DONG, B.; ZHANG, Q.; FANG, H.; YU, Y. Carbendazim induces a temporary change in soil bacterial community structure. Journal of Environmental Science, v. 21, p. 1679-1683, 2009.

YU, Y.; CHU, X.; PANG, G.; IANG, Y.; FANG, H. Effects of repeated applications of fungicide carbendazim on its persistence and microbial community in soil. Journal of Environmental Science, v. 21, p. 179-185, 2010. 
ZHOU, N.; CHEN, N.; LU, J.; FANG, F.; GUO, J. Analysis and Evaluation of Sediment Pollutant of Secondary Rivers of the Three Georges Reservoir. Procedia Environmental Science, v. 10, p. 2147-2152, 2011.

Recebido em: 02 de junbo de 2015 Acesso em: 23 de agosto de 2015 